Western University

Scholarship@Western

FIMS Publications

Information \& Media Studies (FIMS) Faculty

2011

\title{
Ontario public libraries, accessibility, and justice: A capability approach.
}

Heather Hill

Western University, hhill6@uwo.ca

Follow this and additional works at: https://ir.lib.uwo.ca/fimspub

Part of the Library and Information Science Commons

Citation of this paper:

Hill, H. (2011). Ontario public libraries, accessibility, and justice: A capability approach. Canadian Journal of Information and Library Science 35(4), 213-225. 
Title: Ontario Public libraries, accessibility, and justice: A capability approach

\begin{abstract}
The Access for Ontarians with Disabilities Act is developing standards for accessibility across the province. The Canadian Library Association has had service standards in place since 1997, so addressing accessibility in Ontario libraries is nothing new. Public libraries are, however facing new challenges to providing service as they transition from non-binding library association policy to binding legislation. This paper outlines a study of accessibility in Ontario public libraries through a capability approach lens as described by Amartya Sen.
\end{abstract}

\title{
Introduction
}

Addressing accessibility for persons with disabilities is not a new concern for Canadian libraries. The Canadian Library Association has had a policy statement on accessibility in place since 1997. There is, however, a shift happening for Ontario from the guidance of a non-binding, library association policy to binding legislation addressing accessibility.

The recent Access for Ontarians with Disabilities Act (AODA) is shaping the idea of what it means to be accessible in the province. The legislation is divided into five parts, to be implemented over 20 years (Ontario Ministry of Community and Social Service 2011). The first aspect, customer service, went into effect in January of 2010. Future pieces of the legislation cover the topics of the built environment, employment, transportation, and information and communication technologies (ICTs) (Ontario Ministry of Community and Social Service 2011).

The introduction of the AODA has created discussion in Ontario on what it means to be an accessible library and concerns over what future pieces of the legislation will require. Described here is a three-part study of Ontario public library accessibility using a theoretical framework that could be a useful tool for conceptualizing accessibility in public libraries. 


\section{Theoretical framework}

The framework used here for examining accessibility in Ontario public libraries is Amartya Sen's capability approach. Sen first presented this idea in his 1979 Tanner lecture, "Equality of what?" (Sen 1993). In this lecture, Sen proposed that all approaches to justice revolve around the equality of 'something' whether it be measuring the equality of happiness, pleasure, income or wealth. Sen dismisses these as being simplistic and ignoring the complex realities of different people. His approach is based on trying to encompass the heterogeneity of human beings and the large number of variables by which inequality can be judged. Sen's example to illustrate the inadequacies of traditional income-reliant measures is to consider two people who have similar incomes. One is fully able-bodied while the other has a disability that requires special equipment in the form of a wheelchair and a car converted to be accessible. While both have the same income, they vary significantly in their abilities to convert income into achievements (Sen 2009). Instead, Sen proposes the capability approach with its focus on concepts he has designated as 'functionings' and 'capabilities.'

Functionings are the "various things that [a person] manages to do in leading a life (Sen 1993, 31)" - the well-being and actual achievement of a person. Here the focus is on the reality of an individual or group's ability to do something. What can be done?

Capability is defined as a set of functionings that represent the combinations of beings and doings from which a person can choose and thus refers to the real opportunities she has. Here the focus is on how a person's functionings combine to provide her with real opportunities.

A more concrete example is provided Sophie Mitra's (2006) work using the capability approach to examine education for persons with disabilities. She presents the two terms in the form of the 
following questions.

- Capability - "Do persons with impairments have the opportunity to get an education? (239)"

- Functioning - "What is the education level of persons with impairments compared to those without? (239)"

Sen leaves the designation for what functionings and capabilities should be of focus open. He provides little guidance on purpose in order to ensure that the capability approach can be used in a wide range of situations and be capable of helping to address a large number of issues (Sen 2004). For Sen, part of the process of each application of the capability approach would be developing a list of capabilities and functionings. Sen does introduce a few basic capabilities; among them is the ability to be an active participant in the community (Sen 1979,218). His only other guidance for developing lists of capabilities and functionings is that they should come from a Habermasian, communicative action-style approach to democratic deliberation (Sen 2009). Of particular concern for the capability approach is that those who will be affected by the outcome should have a say in what is important to consider in policy creation (Terzi 2009).

A broad view of the capability approach as it relates to accessibility provides two significant perspectives. Accessibility viewed through the capability approach presents accessibility issues as a matter of justice. Additionally, the focus of the framework is on what people can actually be and do, so the capability approach differentiates token from true accessibility (Sen 2009). While new to LIS, the capability approach has been used in feminist studies, disability studies, public policy work, and development studies, particularly in looking at disparities of wealth and nutrition. 


\section{Research questions}

Assigning a full list of capabilities or functionings in order to assess public library service for persons with disabilities is beyond the scope of this paper. Instead, some basic aspects of the capability approach, the ability to be an active participant in the community, that those most affected by a policy should have a hand in its creation, and that the focus should be on true accessibility, are used in order to examine Ontario public library service to persons with disabilities. Of particular interest for this study are the following questions.

- How are library policies, procedures, and services for services to persons with disabilities determined?

- What level of service is currently available?

- How is the capability approach of being an active part of the community manifest in the public library?

\section{Literature Review}

The library literature on accessibility is broad, but when the focus changes to research on accessibility, the scope narrows significantly. The topic of accessibility in the library literature has been characterized as having a dearth of research (Davies 2007; Saumure and Given 2004; Williamson, Kirsty, and Schauder 2000; Williams, Jamali, and Nicholas 2006) and consisting mostly of descriptive work that recommends solutions to particular issues (Davies 2007).

Research on accessibility issues in a Canadian library or information context is rare. The majority of the library literature on accessibility comes from the United States and presents the subject from the perspective of the American with Disabilities Act (ADA) and other US focused 
policy lenses (Hill 2011). This trend is echoed in the broader disability literature. Burns and Gordon found approximately three times as much literature focused on the US than focused on Canada (2010).

The US perspective, residing within the context of the ADA, does provide interesting insights into examining accessible library service in Canada. The ADA has been in place since 1990, yet there are still discussions in the library literature about accessibility challenges. Librarians working with the National Library Service for the Blind and Physically Handicapped noted that information technology and human resources were still major challenges to providing service (Bonici, Matta, and Wells 2009). Additional challenges reside in the areas of collections and services as well as users and policy making. Collections were seen as lacking accessible formats while there were significant concerns that libraries were not identifying persons with disabilities in their communities and were not developing written policies that addressed services to persons with disabilities (Khailova 2005). This research highlights some of the challenges US libraries face more than fifteen years after disabilities legislation has passed and demonstrates a need for research on accessibility issues in libraries as legislation appears and well after it is put in place.

An examination of Canadian library research on accessibility shows a focus on the accessibility of ICTs, particularly as related to health information. Website accessibility is a concern for the provision of consumer health information, but testing has shown that around $40 \%$ of sites had accessibility errors that could make them difficult to navigate (O'Grady 2005). Along with basic web accessibility is concern that the push to move health information online widens the information gap when large groups of Canadian citizens lack access (Hirji 2004). There has been a push for advocating a rights-based approach to ICT access in Canada (D'Aubin 2004), but there are still access issues. The lack of online accessibility and the push to put health 
information online is compounded by research showing a lack of involvement by persons with disabilities in developing Canadian ICT standards (Stientstra 2006).

Another focus for the literature has been comparisons between US and Canadian policy (Burns and Gordon 2010; Griebel 2003; Epp 2006). As the two countries share a border and many similar characteristics, these comparisons make sense. The lack of federal accessibility legislation in Canada sometimes puts it at a disadvantage in the comparisons. Research, as show above, is rare, but the advocacy literature and descriptive pieces detailing accessibility in Canadian libraries is strong. The journal Feliciter seems to be the biggest home to this trend.

There are numerous broad-based studies of library accessibility in the UK (Goulding and Heaven 2002; Kinnell and Creaser 2001; Harris and Oppenheim 2003; Ryder 2004) and US (Bonnici, Matta, and Wells 2009; Akin and Ross 2002; Burke 2009; Khailova 2005), but a broad view of accessibility in Canadian public libraries is absent. Part of this absence could be due to the lack of federal legislation, but the recent implementation of the AODA does create a new environment for examining accessibility at the provincial level.

\section{Research}

The research consists of a three-part study; a survey of Ontario public libraries, an examination of library websites, and interviews with public library users with disabilities requiring some accommodation. Each angle of the research focused on the capability approach from two perspectives. First, certain aspects of the research were framed with the capability approach in mind. Second, there was a focus on showing how the capability approach might guide public library staff through some of the challenges to providing service discovered during the research.

The survey included both quantitative and qualitative questions, some framed specifically 
through a capability approach lens and others based on general accessibility issues. In February of 2011 the survey was mailed to 242 Ontario public libraries selected in a random stratified sampling from the American Libraries Directory. 72 surveys were returned for a response rate of 30\%. Participation was diverse with respondents from urban (32\%), suburban (7\%), and rural $(61 \%)$ libraries.

Library websites from thirteen public libraries across Ontario were explored to determine the placement of accessibility information within the structure of the websites. The thirteen websites represented rural and urban as well as northern and southern Ontario. Additionally, the policies themselves were examined for acknowledgement of the new legislation and its requirements as well as how the policies addressed the customer service aspect of the AODA.

There were two semi-structured interviews with public library users with differing disabilities. Questions concerned their use and perception of public library services and resources.

\section{Findings}

The findings are presented in three sections.

- how libraries are addressing the basic capability of the ability to be a part of the community;

- how libraries are conceptualizing accessibility, particularly if there was a perception of accessibility as an issue that may need to be addressed beyond potentially limited legal mandates;

- and a proposed way to address the uncertainty surrounding needed changes to improve accessibility. 
The first two sections relate to seeing how accessibility is addressed in libraries coincide with the capability approach. The last relates to how the capability approach may help to address challenges in providing accessible service and concerns by library staff about how to address accessibility.

\section{Part of the community}

The ability to be a part of the community was examined through two means. An examination of the location of accessibility information on the libraries' websites and the experiences of public library users and staff provided two perspectives. Policy represents the stated nature of the organization's approach to accessibility and the perception of the interviewees and survey participants represents the reality.

\section{Policy}

For the libraries' accessibility policies, the focus was on determining inclusiveness by the examining the hierarchy under which accessibility information was subsumed and the categorization of that information on the library's website. The more normalized services and information for persons with disabilities was presented, the more inclusive the library's approach was deemed.

Some public libraries have chosen to utilize their governing bodies' customer service policy in order to be compliant with the AODA. Other libraries take the impetus to create their own. Of the thirteen websites examined, eleven of them had their own up-to-date accessibility policies addressing the customer service aspect of the AODA. This speaks of a strong desire to promote accessible services to the community. The remaining two libraries did not have accessibility policies available online, any information addressing accessibility on their websites, or links to 
the broader municipality or county policies at the time of examination which took place four months after the AODA required public organizations to have a customer service policy addressing accessibility in place.

In website design there is a hierarchy of content. The closer a piece of information is to the first level of the website, the home page, the more important an item is deemed. As websites grow more complex and larger, information gets 'buried' and becomes more difficult to find. Most libraries (8) placed accessibility information on the third level, which requires users to navigate through two links to reach the information. One library placed this information on the second level and two placed it on the fourth level.

Having accessibility information on the website's third level is a strong indication of inclusiveness. The third level is consistent with the positioning of other services to patrons which adds to the inclusive nature of this level. Placing accessibility information at the fourth level makes the information more difficult to find and its complete absence removes the ability of community members to easily ascertain what services and resources are available.

How an item is categorized provides additional clues to the approach of the individual library and its possible perception by patrons. The libraries' approaches to accessibility were assessed based on the naming conventions of the links necessary to navigate in order to find accessibility information. Link paths were designated as either community-focused or library focused with community-focused paths being deemed more inclusive than library-focused paths. Paths focused on the community used naming conventions like 'services' geared towards helping users to access information useful to them. Library-centric paths were designated as those like 'about the library' that were focused more on describing the library. Putting community focused 
information on library-focused web pages creates difficulties in finding the information and may represent a task the library had to accomplish versus a task chosen to provide more information to users.

Most of the websites examined (7) had accessibility information under the services area of the website using community-focused names with titles like 'services' or 'library services.' Two websites had the information under library-focused links titled 'about my library' and 'library information.' One provided a mix where the initial link was titled 'using your library,' but navigating to the information on accessibility required users to follow another link titled 'policies' - a considerably library-centric location. As mentioned above, two libraries did not have accessibility information available on their websites.

The structure of most of the library websites shows a trend towards inclusiveness. Placing information on particular services or information related to accessibility at the same level of information as other services for users indicates a desire to mainstream services to persons with disabilities with those of other community members.

\section{Perception}

The second aspect of examining the ability to be a part of the community lay in determining the challenges persons with disabilities face when they access the library and their perception of the

public library they used most frequently. When asked if there were perceived barriers that inhibit use of the library both ICTs and the built environment were mentioned by interviewees and survey participants.

ICT criticism often concerned the adaptive hardware, software, and adaptive workstations and enveloped both the physical environment and technology. Adaptive workstations commonly 
consist of various accessible software and equipment at a designated computer work station. Adaptive software consists of screen readers like JAWS and screen magnifiers as well as other software. Equipment on adaptive workstations commonly consists of a combination of tools such as handheld or frame-mounted magnifiers, amplification equipment, CCTVs, Braille printers, scanners, page turners, large monitors, and reading machines.

Differing perceptions of the location of the adaptive workstation provided an interesting insight into how a desire to be accessible can be perceived as the opposite. The location of the adaptive workstation in the library as well as the age of the equipment was noted by one participant. In her library the adaptive workstation was tucked away in a corner, far removed from other public services computers. The isolation of the adaptive workstation made the interviewee feel disconnected from the rest of the library's patrons. Additionally, some of the equipment was outdated to the extent that it was difficult to use effectively. A library staff member from a different library mentioned the reasoning behind the decision to situate the adaptive workstation away from other public services. The workstation was positioned in a separate area in case the person who used it wanted to work in a quiet environment. The patron and library manager perceive the same phenomenon from vastly different perspectives. The same patron noted that another library she used did not have a screen reader available for use which negated her ability to use the computers and thus the catalogue in the library. Instead, she used the library's OPAC from home using her own screen reader, before venturing to the library.

The physical environment also provided challenges and was a topic of concern for both library users and staff. For a wheelchair user there was a concern about magazine shelving being difficult to access and a desire for wider aisles and "looser corners" for wheelchairs. A library staff member commented on the physical challenges of their library, "we are a multi-level 
building. No elevator. People with assistive devices for walking need to exit through the upper level and walk down the sidewalk to get to lower level for washrooms."

Beyond the gaps identified by patrons with disabilities and library staff, there may also be an unconscious bias that service to persons with disabilities is beyond the regular scope of library services. Segmenting the population requiring accommodation from those who do not, can result in certain perceptions like the following, "We don't have enough sources to even serve the abled population!" While the sentiment expresses a frustration at an overall lack of resources, it can be perceived as somewhat derogatory and exclusionary. There is doubt that the same phrase would be used to distinguish the difficulties of providing resources for children as well as for adults.

Based on the layout of the libraries' websites and the positioning of accessible services information, there seems an effort to incorporate services for persons with disabilities into the community. Even the negative situations outlined above represent no real ill will on the part of public libraries, but simply a lack of resources and other barriers that help deter persons with disabilities feeling a part of their community in public libraries. In some cases there is an attempt to address a challenge, but upkeep can become an issue. Adaptive software and equipment are often significant expenses and, unfortunately, the web design world moves at a much faster development pace than adaptive design which is inherently reactive. Some of the difficulties outlined above may be addressed in the upcoming sections of the AODA. Until that time there are some significant impediments to creating a sense of community for persons with disabilities in the public library.

\section{Looking broader than the legislation}

Using the capability approach requires a focus on the plurality of people's experiences and 
allows examination of an individual or specific group's experiences. Such a framework requires a notion of true, as opposed to token, accessibility. It requires looking beyond the letter of the law and considering the potential flaws of legislation. The capability approach allows the examination of different types of access issues and the ability to notice significant disparities.

As an example particular to Canada, there is a difference in the available resources for persons with visually disabilities versus those available to persons who otherwise have vision, but are print disabled. In Canada there is no national library service charged with providing materials in accessible formats to persons with disabilities. The Canadian National Institute for the Blind (CNIB) is a charitable organization that provides accessible materials and resources for persons with vision impairments. As their mandate deals with vision impairment, the organization has certain limitations to providing direct access to its collection to persons who do not have visual disabilities.

The CNIB has, however, taken steps to provide service beyond persons with visual disabilities and to the broader category of those who have print-disabilities through the VISUNET CANADA program. In Ontario, individual library systems can partner with the CNIB to join the program. Partner libraries are charged a cost-recovery fee necessary to expand the CNIB collection in order to serve the libraries' community (Paterson 2003).

Libraries that become a part of VISUNET Canada provide a needed service to persons who would otherwise have fewer resources and are helping to fill a gap in service to persons in participating provinces. $64 \%$ of the participants indicated that their library had a partnership with the CNIB. Of those, 15 had entered into the partnership within the last 6 months. New CNIB partnerships show a strong desire to increase the resources available for a vulnerable population 
that may otherwise remain uncovered by legislation.

Along with a nuanced approach to print disability, the capability approach requires going beyond legislation that may over-emphasize particular disabilities. There is a perception that the AODA focuses much more on those with physical disabilities over those with mental disabilities. As one participant noted:

"Making public libraries accessible for all is a must! We have 100s or 1000s of mentally disabled patrons and AODA barely addresses their needs. Even the most physically accessible library will see more mentally disabled than physically disabled on any given day. Another example of how poorly served the mentally disabled are."

The perception that the AODA provides little guidance in addressing the needs of persons with mental disabilities creates a significant gap in library services unless addressed beyond the scope of the legislation. A solution to this particular challenge is beyond the scope of this paper, but the fact that this challenge is on the radar shows a desire to look beyond the limits of the legislation. As shown above, many public libraries have already acknowledged the importance of looking beyond the legislation and a conscious use of the capability approach could increase this perspective.

\section{Participation of those with disabilities}

A basic component of the capability approach concerns who participates in policy making. Sen states that the process should be communicative and that those who are most affected by the policy should be significant participants in determining policy focus (Sen 2004). In the language of the capability approach this idea translates into an understanding of the functionings and capabilities important for persons with disabilities in the community that could be supplemented 
or supported by library service. Of consideration here is the participation of persons with disabilities in the creation of library policies, approaches, and services that affect them.

The survey participants seemed uncertain about the services and resources that might be needed to support the persons with disabilities in their communities. There was also concern about what the future might hold as the next four components of the AODA become law. The focus of the comments was the legislation; how various aspects of accessibility would be defined and what changes might be needed to come into compliance with the legislation. Some of the participants' libraries were very proactive, having long standing disability service policies and approaches, while others were waiting to see what legislative demands were made before moving forward.

As the legislation will determine the legal definition of what accessible means in different contexts and what accommodations are required by law, this approach makes sense. But what has not been a part of the majority of these libraries' approaches has been a dialogue with their communities. A dialogue with the community concerning who in the community has what disabilities and what services and resources are necessary to address their needs and wants would be a significant step in resolving this uncertainty. It would also puts the community members with disabilities in a place of power in developing policy directed towards them.

At the provincial level, the AODA does include individuals with disabilities and disability interest groups in the decision-making bodies, so the overarching framework for the legislation does include the perspective of persons with disabilities. At the local level of the public library and its community, however, this participation is absent. In a question asking if the library had done any local surveys to try to identify persons with disabilities in the community $91 \%$ said no.

At the same time, some survey respondents indicated that they were unsure about their 
communities' needs and requested guidance on what kinds of accessible software, hardware or other adjustments they could make. One participant noted a desire to provide more services, but a seeming gap in knowing community needs. "We serve the needs of the disabled who are currently using the libraries but I am sure there are more who would use our services if we were better equipped." Another expressed their confusion by saying, "need someone to say, "here are the best products."”

Other respondents seemed to be disconnected from any impetus to determine the needs of persons with disabilities in the community, "not aware of anything people want...Most patrons with disabilities don't require major accommodations. Don't know about disabled who don't use the library." Along the same lines, a different participant presumed it was the individual community member's responsibility to initiate the accessibility conversation. "More changes would be made if asked for."

The AODA will be a significant factor on library services, but identifying and connecting with persons in the community with disabilities would be a vital source in determining what services or resources would be valued. Integrating a capability approach to accessible services could also help change the perspective of those who believe that accessibility should be a patron initiated event. The capability approach, in requiring the participation of those most affected by the outcome of the policy or program, would be of immense use in helping to resolve some of the uncertainty outlined above.

\section{Discussion}

The capability approach can provide greater insight into public library service for persons with disabilities. The framework provides a broad perspective that demands looking beyond possible 
limiting legislation and it positions accessibility as a matter of justice. Through an active approach to policy creation, to an understanding of some of the shortfalls in current library service, Ontario public libraries are making significant strides towards including persons with disabilities in the community of the library. The values of the capability approach, significantly the need to differentiate true accessibility from token accessibility, provide strong insights into the needs of public library service. The survey participants showed an understanding beyond the limits of the legislation. Many libraries are looking beyond the limitations of the legislation and instituting partnerships to provide a broader level of service to groups that may not be of focus for the disabilities legislation. There are still significant barriers, some due to the limitations of the current built environment or available technology, but others that are more human oriented in how accessibility is conceptualized.

This research has made a few connections between public library service to persons with disabilities and the capability approach as outlined by Sen. To further develop the use of this framework for public library service provision, the library community and community members would need to work together to develop a list of capabilities and functionings specific to public library service. 


\section{References}

Akin, Lynn and Virginia Ross. 2002. "Children with learning disabilities and public libraries: an e-survey of services, programs, resources and learning." Public Library Quarterly 21: 9-18.

Bonnici, Laurie, Stephanie Matta, and Muriel Wells. 2009. "US national accessibility survey: Librarians serving patrons with disabilities.” New Library World, 110: 512-528.

Burke, Susan. 2009. "Perceptions of public library accessibility for people with disabilities." Reference Librarian 50: 43-54.

Burns, Katherina Kovacs and Gary L. Gordon. 2010. “Analyzing the impact of disability legislation in Canada and the United States.” Journal of Disability Policy Studies 20: 205-218.

D’Aubin, April. 2007. "Working for barrier removal in the ICT area: Creating a more accessible and inclusive Canada. A position statement by the Council of Canadians with Disabilities." Information Society 23: 193-201.

Davies, J. Eric. 2007. “An international overview of international research into the library and information needs of visually impaired people.” Library Trends 55: 785-795.

Epp, Mary Ann. 2006. “Closing the 95 percent gap: library resource sharing for people with print disabilities." Library Trends 54: 411-429.

Goulding, Anne and Suzanne Heaven. 2002. "Higher education libraries and SENDA.” New Review of Academic Librarianship 8: 175-194.

Griebel, Rosemary. 2003. "If Hellen Keller lived north of the $49^{\text {th. }}$. Canadian library services for people with disabilities." Feliciter 49: 155-157. 
Harris, Clare and Charles Oppenheim. 2003. "The provision of library services to the special educational needs and disabilities act." Journal of Librarianship and Information Science 35: 243-257.

Hill, Heather. 2011. Levelling the playing field: Situating the discourse of accessibility in LIS. Presentation given at the Association of Library and Information Science Education conference, San Diego, California.

Hirji, Faiza. 2004. "Freedom or folly? Canadians and the consumption of online health information." Communication \& Society 7: 445-465.

Human Resources and Skills Development Canada. 2009. "2009 Federal disability report: Advancing the inclusion of people with disabilities." http://www.hrsdc.gc.ca/eng/disability_issues/reports/fdr/2009/fdr_2009.pdf

Khailova, Ladislava. 2005. "South Carolinian public libraries' ADA accommodations to persons with disabilities.” Public Library Quarterly 24: 19-46.

Kinnell, Margaret and Claire Creaser. 2001. "A new outlook? Services to visually impaired people in UK public libraries. Journal of Librarianship and Information Science 33: 5-14.

Ontario Ministry of Community and Social Services. 2009. "Making Ontario accessible." http://www.cfcs.gov.on.ca/en/mcss/programs/accessibility/index.aspx . (2011). Access for Ontarians with Disability: Other standards. http://www.mcss.gov.on.ca/en/mcss/programs/accessibility/other_standards/index.aspx. Mitra, Sophie. 2006. "The capability approach and disability." Journal of Disability Policy Studies 16: 236-247. 
O’Grady, Laura. 2005. “Accessibility compliance rates of consumer-oriented Canadian health care web sites." Medical Informatics \& the Internet in Medicine 30: 287-295.

Paterson, Shelagh. 2003. "CNIB for the blind: Placing library service for the blind in the community." http://www.collectionscanada.gc.ca/accessinfo/005003-3020-10-2001-e.html

Prince, Michael J. 2004. “Canadian disability policy: Still a hit-and-miss-affair.” Canadian Journal of Sociology 29: 59-82.

Ryder, Julie. 2004. “Can't get to the library? Then we'll come to you. A survey of library services to people in their own homes in the United Kingdom." Health Information and Libraries Journal 21: 5-13.

Saumure, Kristie and Lisa Given. 2004. Digitally enhanced? An examination of the information behaviours of visually impaired post-secondary students. The Canadian Journal of Information and Library Science 28: 25-42.

Sen, Amartya. 1979. "Equality of what." The Tanner Lectures on Human Values. 1992. Inequality Reexamined. Cambridge, Mass.: Harvard University Press. . 1993. "Capability and well being." in The quality of life, ed. Martha Nussbaum and Amartya Sen. New York: Oxford University Press. . 2004. "Dialogue: Capabilities, lists, and public reason: Continuing the discussion." Feminist Economics 10: 77-80. .2009. The idea of justice. New York: Harvard University Press.

Stienstra, Deborah. 2006. "The critical space between: Access, inclusion and standards in 
information technologies." Information, Communication \& Society 9: 335-354.

Williams, Peter, Hamid Jamali, and David Nicholas. 2006. “Using ICT with people with special education needs: What the literature tells us." Aslib Proceedings 58: 330-345.

Williamson, Kirsty, Don Schauder, and Amanda Bow. 2000. "Information seeking by blind and sight impaired citizens: An ecological study.” Information Research 5. 